\title{
ROLE OF PRESCHOOLERS IN MOTIVATION FOR PHYSICAL ACTIVITY IN THEIR FAMILIES
}

\author{
KRZYSZTOF PIECH ${ }^{1}$, RAFAŁ GRAD ${ }^{2}$ \\ ${ }^{1}$ Józef Piłsudski University of Physical Education in Warsaw, \\ Faculty of Physical Education and Sport in Biała Podlaska, Department of Recreation \\ ${ }^{2}$ Jędrzej Śniadecki Academy of Physical Education and Sport in Gdańsk, \\ Faculty of Physical Education
}

\author{
Mailing address: Krzysztof Piech, Faculty of Physical Education and Sport, Department of Recreation, \\ 2 Akademicka Street, 21-500 Biała Podlaska, tel.: +48 83 3428748, fax: +48 83 3428800, \\ e-mail: krzysztofpiech@wp.pl
}

\begin{abstract}
Introduction. Family-oriented strategies of promoting physical activity are underused. In the last few years there has been a significant decrease in number of research on family as a promoter of physical activity. The research, when conducted, focuses on the influence parents' activity has on that of their children. There is a need for assessment of child's influence on parents' physical activity. Material and methods. The survey utilises an opinion poll in the form of a questionnaire. The sample consisted of 100 parents who were invited together with their children to a recreational fair. Results. The survey shows that child may be the person encouraging their parents to active recreation. Symptoms of this are: encouraging the parents to take part, satisfaction with the decision to take part in the event and the amount of positive sensations during play. The parents were of opinion that their both, children's as well as teacher's encouragement, was the most important factor in their decision to participate. Conclusions. The research indicated that after the fair children encouraged their parents to play together, whereas parents used games from the fair in their family free time. Because of the fact that the offered model of recreational event for families engaged and interested the participants, it is worth promoting in pedagogical sphere.
\end{abstract}

Key words: physical activity, child, family

\section{Introduction}

Within the past few years there has been increasing talk of young generation aversion for activity. There is significant increase of absence from physical activity classes in all levels of education in our country. At the same time, there is a significant increase of interest in physical activity among the middle-aged and the elderly. This is especially visible during amateur sport events, where the largest age brackets are over 40 . The trend has reversed from the seventies and eighties, when the young generation (especially in primary schools) showed much more physical activity and the physical education class was the best liked one. Parents' activity was limited to occasional work in their allotments and walks. We may wonder where have the correct rules of bringing up active youths gone. The change in physical activity behaviour in today youths should prove a challenge for both teachers and parents. Among the publications on physical activity in families we may find works on the influence parents' physical activity has on activity of their children, as well as very few works concerned with the children's physical activity on this of their parents [1, 2, 3, 4, 5]. According to Brustad [5] the very significant potential family has for promotion of physical activity is not being used in its full capacity. At the same time O'Connor and his colleagues [6] notice the decrease in number of surveys upon the family influence on promoting physical activity. Despite the limited data, the positive effects of familybased strategies are noticeable. The main purpose of the survey was assessment of the preschool child's role in motivating the physical activity of their family.

\section{Material and methods}

The survey was conducted in the year 2013 on 100 parents partaking alongside their children in the XXI Preschool Olympics in Biała Podlaska. The method utilised was an opinion poll, using a questionnaire (child as the animator of family physical activity). The parents were asked to fill in the questionnaire at their homes, to be collected by the teacher. The researchers decided to determine whether the participation of parents in recreational events is motivated by the child. With this goal in mind, the parents were invited to a recreational event (Family Preschool Olympics) organised by the students of the Faculty of Physical Education and Sport in Biała Podlaska, with about 200 games designed to amuse entire families. Rivalry was left out of the games as inadvisable for preschoolers.

$75 \%$ of the surveyed parents declared to have tertiary level education. It must be emphasised that most of the surveyed parents were mothers (72\%). The surveyed declared that their spouses have also participated in the event (77\%), as well as the grandparents and siblings. This shows family character of the event. $67 \%$ of the parents actively partook in the games, as opposed to assisting their children. 


\section{Results}

Table 1 itemises the forms of physical activity partaken in by parents, children and other members of the families. These are the most common forms often specified in other research [7].

Table 1. Forms of physical activity partaken in by members of families

\begin{tabular}{|l|c|c|c|c|}
\hline \multicolumn{1}{|c|}{ Activity } & Parents & Child & Grandparents & Sum \\
\hline Cycling & 101 & 63 & 31 & 195 \\
\hline Swimming & 61 & 54 & 5 & 120 \\
\hline Walks & 95 & 59 & 38 & 192 \\
\hline Jogging & 7 & 4 & 3 & 14 \\
\hline Nordic walking & 4 & 0 & 7 & 11 \\
\hline Fitness (Pilates, Zumba, etc.) & 22 & 4 & 2 & 28 \\
\hline Gym workout & 19 & 0 & 0 & 19 \\
\hline Others (specify) .............. & 11 & 14 & 1 & 26 \\
\hline
\end{tabular}

Also interesting for the survey seems the amount of time spent by the parents on physical activity. Unfortunately, the surveyed group is not a physically active one. Only $8 \%$ of the parents partake in physical activity three times a week, $20 \%$ once a week, the reminder declaring their physical activity to be sporadic. This seems alarming in young people with small children. Besides setting the wrong example for their children, these people neglect their own health.

The researchers decided to question the surveyed group on who had an influence on their present attitudes towards physical activity. As seen in figure 1, the peer group had most significance in this matter. It should, however, be taken into consideration that the group surveyed is not particularly interested in this way of spending their free time.

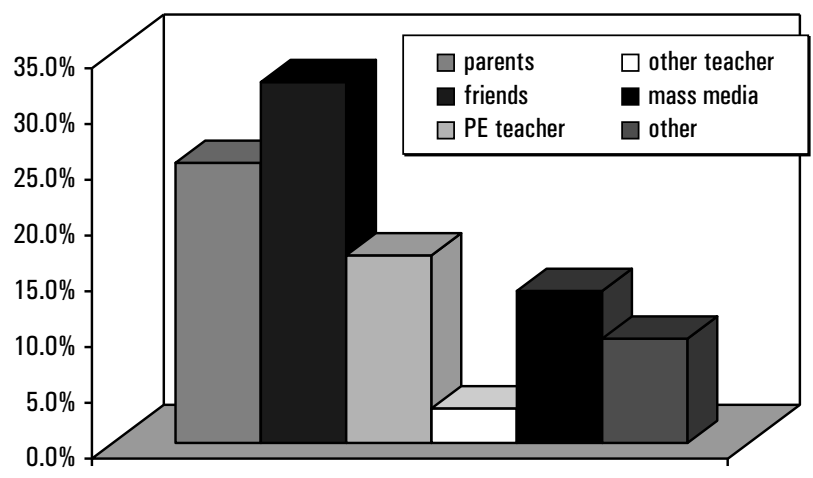

Figure 1. Who influenced the attitudes towards physical activity in the surveyed group

The parents declared playing with their children. It has to be emphasised, however, that play was not a regular activity. It usually encompassed ball games, cycling and walks. It is alarming that $15 \%$ of the parents undertake no physical activity with their children, being of the opinion that preschool and other organisations provide sufficient physical activity (fig. 2).

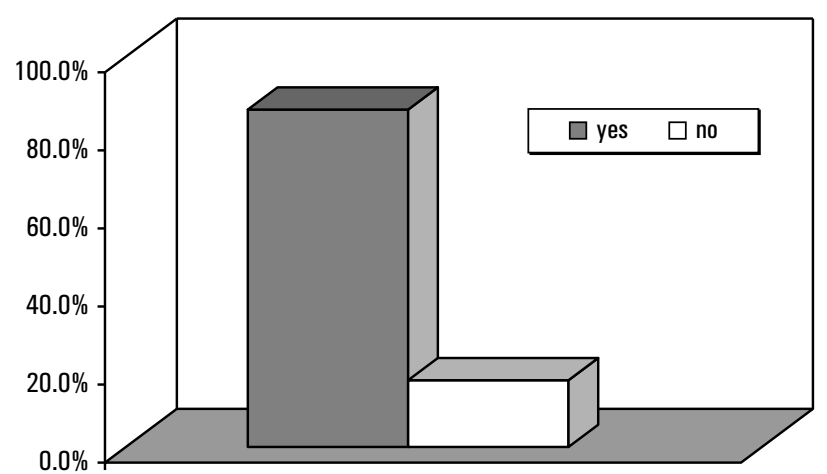

Figure 2. Physical activity shared by children and parents prior to participating in the preschool Olympics

Very significant for the survey is the information provided by parents on the making of the decision to participate (fig. 3). As the organizers predicted, the greatest influence was the notification by the preschool teacher, but the children notified their parents of the event as well. The preschool teachers were charged with inviting and providing the details about participation in the event during parent-teacher meetings.

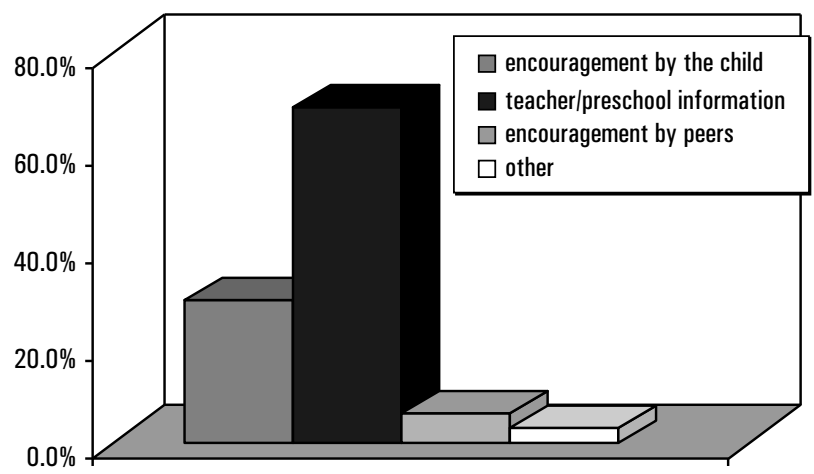

Figure 3. Decision to participate in the event

The parents declared children to show very much satisfaction after they decided to participate in the event (fig. 4). However, there were no negative children's reactions observed.

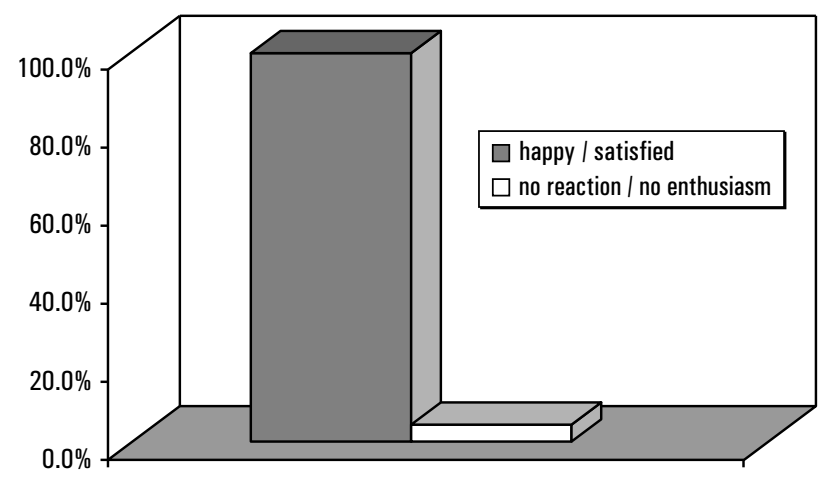

Figure 4. Reactions to decision to participate in the event 
The parents declared very positive memories of the event. This is significant both for the organisers, showing them the choice of games and attractions was satisfactory for the participants, as to the further participation in similar events and encouragement to physical activity. What seems alarming is that $17 \%$ of the parents declared their participation to be out of their sense of duty towards the children (fig. 5). This percentage is similar to this of parents who have admitted to sharing no physical activity with their children.

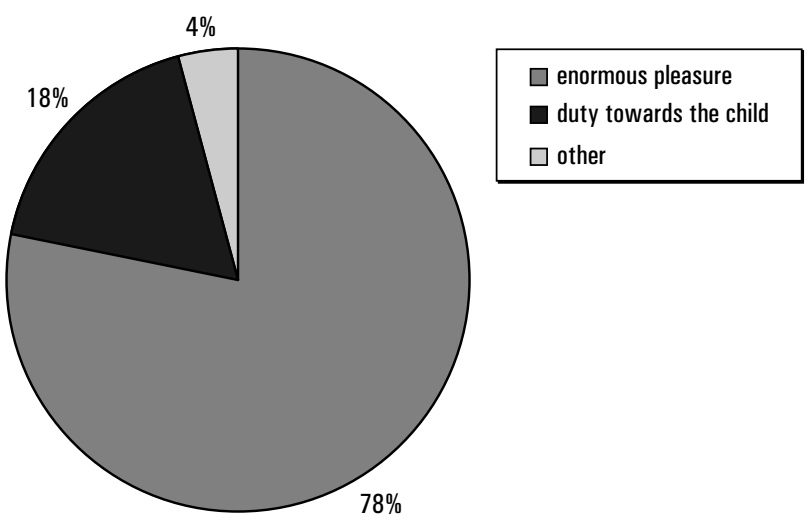

Figure 5. Memories of the event

Also interesting from the organisers' point of view were the participants' impressions. The parents spoke of participating in the games together with children, the children partaking in competitions and the games. Those choices are important, as they point towards the family need for integration through play. Value placed on them by the parents indicates a correct attitude to raising children (fig. 6).

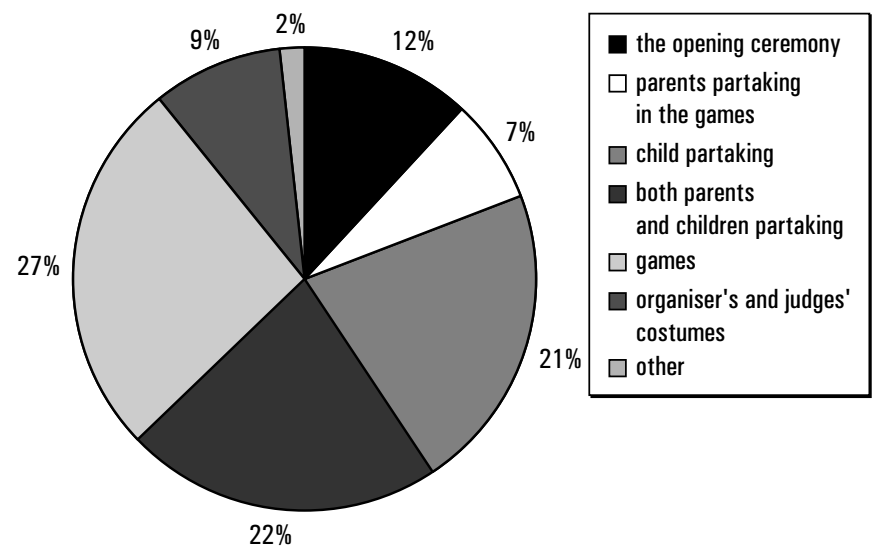

Figure 6. Parents' impressions after the event

The parents also spoke of their children's impressions. As their parents, the children liked the games, playing together with parents, parents taking part in the games, themselves partaking, and also the organisers' costumes. The parents' relations of children's positive impressions and memories show that there were reflections after the event, which became the basis of family discussions. For a more thorough view of the problem, the parents were questioned on what part of the event they liked best. The answers were similar. The parents mentioned playing along with their children, the atmosphere, the games (fig. 7).

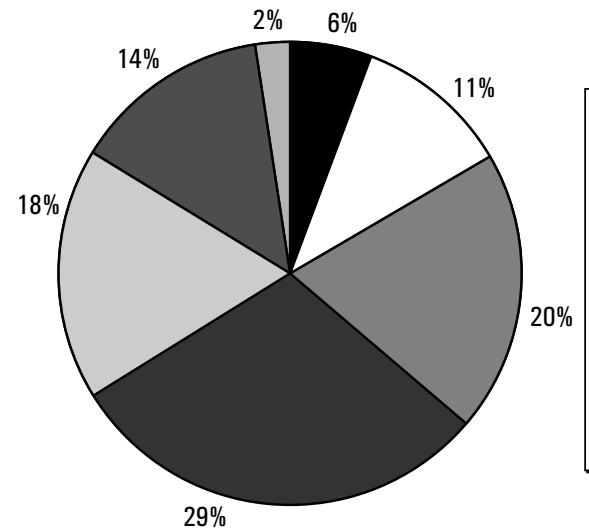

the opening ceremony

$\square$ parents' participation in games

$\square$ own participation

games

$\square$ organiser's and judges'

costume

$\square$ playing together with parents

$\square$ other

Figure 7. Children's impressions of the event

Figure 8 depicts the data on the Olympics' influence on the future physical activity. More than $75 \%$ of the parents have declared that the event may have influence on the future physical activity. For about $24 \%$ the event was not an inspiration for increasing the amount of physical activity shared by the family. Therefore, other ways of changing that should be sought. Without doubt, there is a significant need for education of the parents.

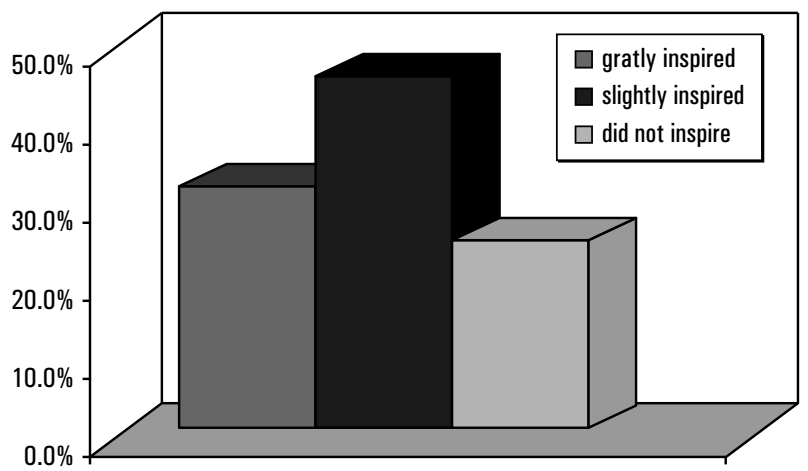

Figure 8. How did the participation in the event inspire families to physical activity

The next issue seems quite interesting (fig. 9). The surveyed report different degrees of inspiration among members of the family. What seems intriguing is that the most inspired group were children. Movement is a natural activity for preschoolers. To limit movement stands against the rules of pedagogy and physiology. Parents reporting the children to be the most encouraged to physical activity may indicate previous parental neglect in the regard of the children physical activity. It may also indicate needs in this regard. 

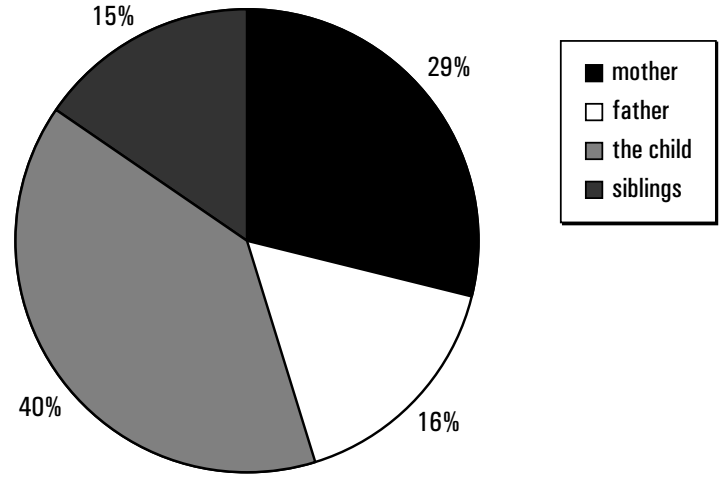

Figure 9. Who in the family was inspired to physical activity

Participation in various forms of physical activity requires the use of sports equipment, not necessarily of the expensive sort. One of the Olympics goals was to introduce games without any equipment, so they can be easily bought and played at home. It is significant that $25 \%$ of the participating families bought equipment, mostly balls, bicycles, skipping ropes (fig. 10).

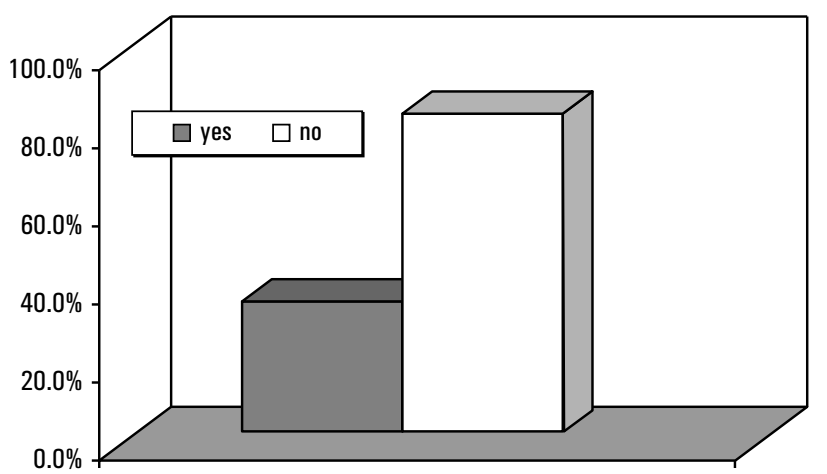

Figure 10. The Olympics as an inspiration for buying sports

The Olympics has left an impression in both, children and parents' memories. The parents declared that the children initiated conversations about the fair after coming home from the preschool (fig. 11)

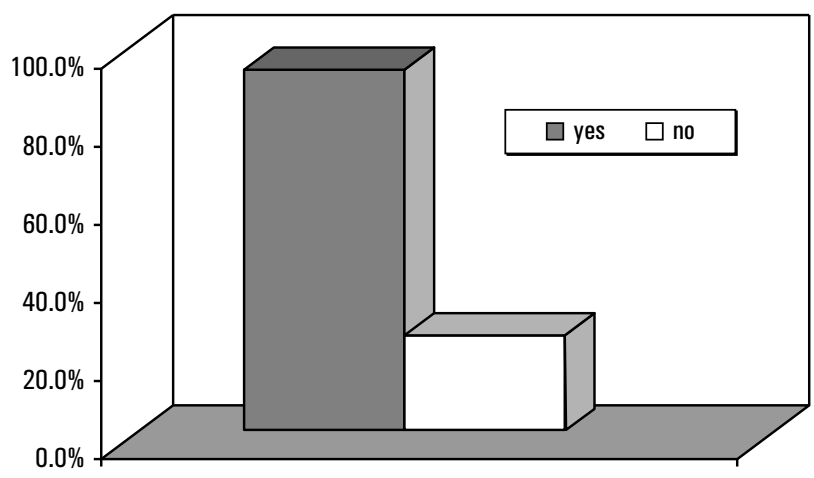

Figure 11. Did the child speak about the Olympics
Parents were also enabled by their participation in the event to start discussions among family. Over $82 \%$ took it as an occasion to speak with their children (fig. 12). Referring to positive events from the family past is an integrating and unifying factor.

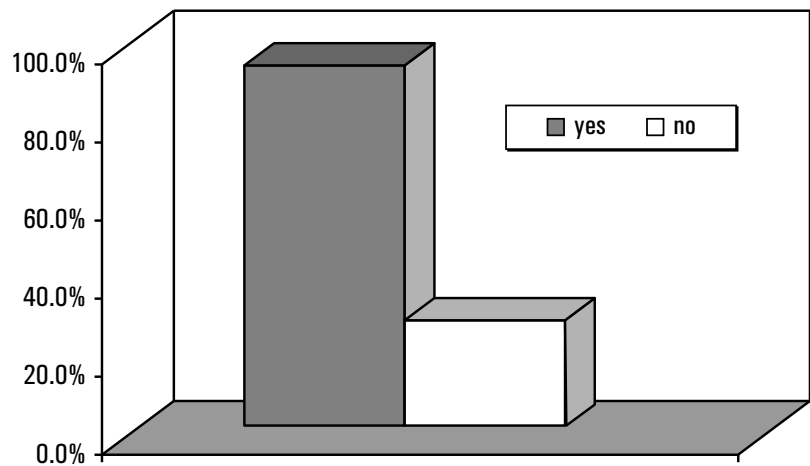

Figure 12. Did parents speak about the Olympics

Over $77 \%$ of the parents have informed the researchers that they have photographic documentation of the event. It is important, as photographs of such kind are commonly viewed within the circle of family and friends. It serves not only promotion of future events, but also enables the participants to remember and relive the fair. We suspect it may have an influence on family's behaviour during free time.

Also important is that over $97 \%$ of the parents have declared will to participate in similar events in the future together with their children. The most commonly given answer was once or twice a year, but some parents expressed a need to do it even once a month.

The question of encouragement for shared play provided by the child to the parents seems important from the point of view of the motivation for physical activity in family. $77 \%$ of the children were declared by their parents to encourage them to play together (fig. 13).

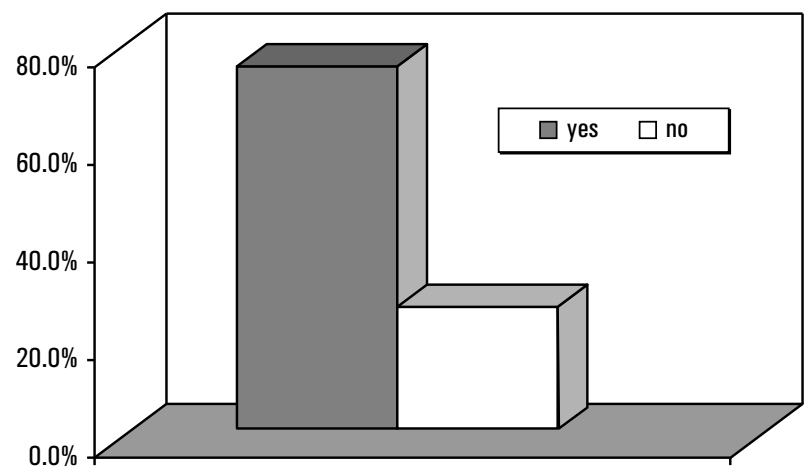

Figure 13. Did the child encourage parents to play together after the event

Also important seems that over $70 \%$ parents utilise the games learned at the Olympics during everyday play with their child. The event has served its educational purpose. The parents also declared plans to further encourage their children's physical activity by additional recreational activities. 


\section{Discussion}

The issue of children's physical activity influence on that of their parents is undertaken much less often than its reverse. Polish and foreign researchers both examined the parents' influence on their children's physical activity much more often. Sadowska [8] noticed a correlation of current physical activity undertaken by parents and the activity levels in their children. Parents' physical activity has more significance than verbal encouragement. This opinion is shared by Sallis and Pate [9], who claimd that stronger connection between children's and parents' levels of physical activity may be expected when the parents not only encourage their children to physical activity, but also partake in it together with the child. This is supported by the research conducted by Piech and Michałowska [10] on participation of one member of a family in running events, which was shown to motivate other family members to take an interest in physical activity, both as spectators at running events and as active participants.

The parents surveyed were not physically active before participating in the fair. Only 8\% partook in physical activity thrice a week, $20 \%$ - once a week, activity of the remainder being sporadic. Other surveys on the subject yielded similar results [11, $12,13]$. It is also confirmed by the Mogiła-Lisowska survey, indicating low levels of physical activity among adults. The existing activity is irregular. The author emphasises an alarming correlation. The less frequent participation in recreational activity, the bigger part substance use (tobacco, alcohol) plays in the lives of the survey participants [7]. Therefore, families should be given support by organisers and recreation specialists. The offer should be appropriate to family members' ages, but it should accommodate such forms that can be undertaken by all the family members. Other research shows that parents' own activity causes in children lasting motivation towards physical activity [14]. Also Heitzler and his colleagues [15] indicated on stronger involvement of children in physical activity when influenced by the family. Domingues and Goncalves [16] in their research on parents of children talented at sports also found parents' influence to be an important factor for the involvement of youth in sports.

Our survey showed that child may be the person to encourage the parents to active leisure. Children encourage their parents to take part in events, are happy about their decision to do so and have positive impressions from the play. Our survey coincides with earlier research on sport and recreational events as a way of promoting physical activity in families [17]. As in the earlier research, the largest influence on parents' decision to participate was the encouragement by both the child and teachers. In both surveys the parents declared that the factor most important to them has been the child's participation, the child's enjoyment, playing together with their child. These data indicated the possibility of bidirectional influence between parents and children [18]. The process of reciprocal socialisation consists of parents learning from their children - there is a vertical transmission of information pertaining to health from the child to the parents. This phenomenon is poorly understood and has not been the concern of enough studies [1, 2, 3, 17]. Another significant fact is the buying of sport equipment. Over $25 \%$ of the parents declared having done so. During the survey on children's participation in recreational events at preschool with giving homework the parents have declared buying sport equipment as well [4]. It is important to note that, while preschool Olympics only happens once a year, the parents declare having photographic documentation and conversations on the subject during family meetings. It was also an occasion to speak with the children, which is an important factor for unifying the family. Activisation of parents through their children was also noticed by Birontiene [3], who has shown in her survey of parents in
Klaipeda that children participating in a special physical activity program succeed in talking parents into performing homework referring to physical activity. Similarly, the research by Staniszewski [1], showed younger primary school children to be the instigators of physical activity in their homes. The introduction of physical education textbook "Bakcylek sportowy" into the early primary education has increased parents' and children's interest in shared exercise and play. Over $14 \%$ of the surveyed children exercised with the Bakcylek every day, 29.8\% did so two-three times a week, $32 \%$ once a week.

Also important to the subject of this survey seemed to be the fact that over $77 \%$ of the children were encouraging their parents to shared play after the event, and that $70 \%$ of the parents declared their use of games learned at the Olympics during leisure shared with the child. The parents declared further development of their children's physical activity in organised recreation. It would be advisable to cultivate this potential, born of children's natural willingness to undertake physical activity, especially in preschoolers and younger primary students.

The problem is important, because, as was shown by SasNowosielski [18] the surveyed youth does not perceive parents as physically active, the parents do not undertake physical activity along with their children and do not focus family activities upon it. Education of families may yet stop this disadvantageous process. Cooperation of parents with teachers is also worth taking into consideration.

\section{Conclusions}

1. The parents' participation in recreational event turned out to be stimulated not only by teachers but also by children. The research shown that children encouraged their parents to shared play after the event, while parents utilised games learned at the fair during shared leisure.

2. Parents impressions of the fair focused on the child's, as well as the family's, participation in the games. According to parents, most of the children have mentioned games and shared play with parents, parents' participation in the events, organisers' costumes. Also mentioned were conversations with children post the Olympics and the photographic or film documentation. It is an important factor in unifying the family.

3. The model proposed for family recreational event has proven to arouse interest in participants and worth further promotion in pedagogical practise.

\section{Literature}

1. Staniszewski T. (2007). Assumptions and actual function of school in preparation of younger school children to physical recreation in the family. Warszawa: AWF Warszawa. [in Polish]

2. Iannotti R.J. (2005). Prospective analyses of relationships between mothers and children's physical activity. Journal of Physical Activity and Health 2(1), 1-34.

3. Birontiene Z. (2012). A child as a physical activity stimulator in a family. Sporto Mokslas 2(68), 38-44.

4. Piech K., Nowak K., Birontiene Z., Biteniece I.B. (2013). Physical exercises for pre-school children with homework and parents mobilization around these tasks. Polish Journal of Sport and Tourism 20(3), 217-226. DOI: 10.2478/pjst-20130020.

5. Brustad R.J. (2010). The role of family in promoting physical activity. Research Digest Series 10(3), 1-8.

6. O'Connor T.M., Jago R., Baranowski T. (2009). Engaging parents to increase youth physical activity. American Journal of 
Preventive Medicine 37(2), 141-149.

7. Mogiła-Lisowska J. (2010). Recreational physical activity in young Poles - preconditions and lifestyle. Warszawa: AWF Warszawa. [in Polish]

8. Sadowska M. (1992). The importance on spontaneous forms of physical activity in children and adolescents and of early initiation in their educating for physical culture. In R. Przewęda (Ed.), Physical education in Poland (pp. 43-52). Warszawa: AWF Warszawa. [in Polish]

9. Sallis J.F., Pate R.P. (2001). Determinants of youth physical activity. Fitnessgram reference guide. Dallas: The Cooper Institute.

10. Piech K., Michałowska A. (2012). Influence of parents' physical activity on the level of physical activity of family members on example of the Grand Prix Round of South-East Poland Running Competitions. LASE Journal of Sport Science $3(2), 18-27$.

11. Lenartowicz M. (1998). Sport in the family in Eastern Europe and in Western Europe. In Z. Krawczyk, J. Kosiewicz, K. Piłat (Eds), Sport in the process of European integration: the international symposium (pp. 242-247). Warszawa: AWF Warszawa. [in Polish]

12. Kaiser A., Stelmaszewska M. (2012). Parental roles in developing the interest in physical activity in preschoolers. Studia Periegetyka, Zeszyty Naukowe WWSTiZ w Poznaniu 8, 7588.

13. Kaik-Woźniacka A., Fąk T. (2010). Physical recreation in Wrocławian families with young primary school children. In A. Kaiser, M. Sokołowski (Eds), Social and natural environment and human physical activity (pp. 31-40). Poznań:
WWSTiZ in Poznań. [in Polish]

14. Bauer K.W., Nelson M.C., Boutelle K.N., Neumark-Setainer D. (2008). Parental influences on adolescents physical activity and sedentary behaviour. Longitudal findings from Project EAT-II. International Journal of Behavioral Nutrition and Physical Activity 5(12), 1-7.

15. Heitzler C.D., Martin S.L., Duke J., Huhman M. (2006). Correlation of physical activity in a national sample of children aged 9-13 years. Preventive Medicine 42(4), 254-260.

16. Domingues M., Goncalves C.E. (2013). The role of parents in talented youth sport. Does context matter? Polish Journal of Sport and Tourism 20(2), 117-122. DOI: 10.2478/pjst-20130011.

17. Piech K. (2004). Promoting of physical activity in families. Biała Podlaska: ZWWF Biała Podlaska. [in Polish]

18. Sas-Nowosielski K. (2009). The determinants of leisure physical activity in adolescents and their implications for the process of education for participating in physical culture. Katowice: AWF Katowice. [in Polish]

Submitted: June 9, 2014

Accepted: September 1, 2014 